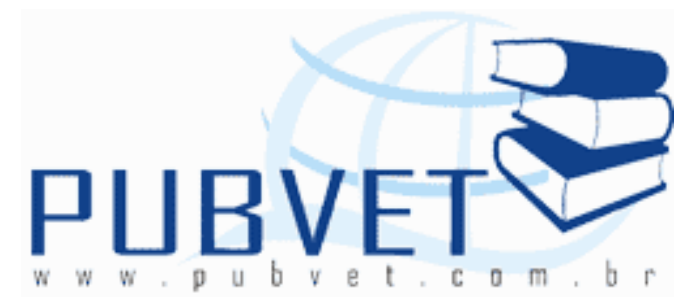

PUBVET, Publicações em Medicina Veterinária e Zootecnia.

Disponível em: <https://doi.org/10.31533/pubvet.v02n10a413>.

\title{
Calagem e adubação de pastagens na Amazônia
}

Newton de Lucena Costa ${ }^{1}$, Valdinei Tadeu Paulino², Claudio Ramalho Townsend ${ }^{3}$, João Avelar Magalhães ${ }^{4}$, Ricardo Gomes de Araújo Pereira ${ }^{2}$

${ }^{1}$ Eng. Agrôn., M.Sc., Embrapa Roraima, Caixa Postal 133, CEP 69301-970, Boa Vista, Roraima

Eng. Agrôn., Ph.D., Instituto de Zootecnia, Nova Odessa, São Paulo

2Zootec., D.Sc., Embrapa Rondônia, Caixa Postal 406, CEP 78900-970, Porto Velho, Rondônia

3Med. Vet., M.Sc., Embrapa Meio Norte, Caixa Postal 341, CEP 64200-000, Parnaíba, Piauí

\section{Resumo}

A pecuária tem sido uma atividade pioneira na ocupação de áreas de fronteira e, nos últimos 30 anos vem sendo incrementada na região Amazônica, transformando segmentos significativos da floresta em pastagens, como consequência da abertura de novas estradas que propiciam condições favoráveis para a ocupação humana na região. No processo tradicional de formação e utilização de pastagens cultivadas na região Amazônica, após a queima da floresta, grande quantidade de nutrientes é adicionada ao solo através das cinzas, aumentando consideravelmente sua fertilidade, elevando o $\mathrm{pH}$ em pelo menos uma unidade e praticamente neutralizando o alumínio 
trocável. Nutrientes como o cálcio e magnésio permanecem em níveis satisfatórios. Em conseqüência, a saturação por bases dificilmente é inferior a $50 \%$. O potássio permanece mais ou menos estável, em níveis adequados para manter a produtividade das pastagens. A matéria orgânica e o nitrogênio permanecem em níveis aceitáveis, apesar das periódicas queimadas. Tal situação perdura por três a cinco anos após o estabelecimento da pastagem. A partir daí, há um decréscimo na produtividade de forragem e incremento na comunidade de plantas invasoras, como consequência da incapacidade da planta forrageira em suprir bons rendimentos em baixos níveis de fertilidade do solo. Deste modo, a reposição de nutrientes através da calagem e adubação é uma prática indispensável para a recuperação da capacidade produtiva das pastagens, com reflexos altamente positivos e significativos na sua capacidade de suporte e, consequentemente, no desempenho animal. No entanto, a adoção de práticas de manejo que envolva a utilização de germoplasma forrageiro com baixo requerimento de nutrientes e com alta capacidade de competição com as plantas invasoras e sistemas e pressões de pastejo compatíveis com a manutenção do equilíbrio do ecossistema, podem ser considerados como a chave para assegurar a produtividade das pastagens cultivadas por longos períodos de tempo, nas áreas de floresta da região amazônica.

Palavras-chave: adubação, Amazônia, calagem, pastagem cultivada

\section{Liming and fertilization of Amazonia's pastures}

\section{Abstract}

The livestock farming has been a pioneering activity in the border areas occupation and, in the last 30 years comes being increased in the Amazonian region, transforming significant segments of the forest in pastures, as consequence of the opening of new roads that provide favorable conditions for 
the human occupation in the region. In the traditional process of establishment and utilization of cultivated pastures in the Amazonian region, after burning of the forest, great quantity of nutrients are added upon soiling through the ash, increasing considerably his fertility, elevating the $\mathrm{pH}$ in at least a unit and practically neutralizing the aluminum trocável. Nutritional as the calcium and magnesium remain in satisfactory levels. In consequence, the saturation by bases hardly is lower to $50 \%$. The potassium remains more or less stable, in adequate levels for maintain the productivity of the pastures. The organic matter and the nitrogen remain in acceptable levels, despite of the frequents burned. Such situation persists during for three to five years after the establishment of the pasture. It leave then, there is a decrease in the dry matter productivity and increase in the weeds plants community, as consequence of the incapacity of the forage plant in supply good performances under low levels of soil fertility. In this way, the replacement of nutrients through liming and fertilizing is an indispensable practice for the recuperation of the productive capacity of the pastures with significant and highly positive consequences in the pasture carring capacity and, consequently, in the animal performance. However, the management practices adoption that involve the utilization of forage germoplasm with lower supply nutrients and with high capacity of competition with the weed plants and grazing systems compatible with the maintenance of the equilibrium of the ecosystem, can be considered like the key for assure the cultivated pastures productivity long periods, in the areas of forest vegetation.

Keywords: Amazonia, fertilization, liming, cultivated pasture

\section{Introdução}

Na Região Amazônica, uma grande proporção de seus solos apresenta elevada acidez, baixa disponibilidade de fósforo $(P)$ e de cátions trocáveis (cálcio, magnésio e potássio), além de alta saturação de alumínio (Al). No 
processo tradicional de formação e utilização de pastagens cultivadas na região Amazônica, após a queima da floresta, grande quantidade de nutrientes é adicionada ao solo através das cinzas, aumentando consideravelmente sua fertilidade, elevando o $\mathrm{pH}$ em pelo menos uma unidade e praticamente neutralizando o alumínio trocável. Nutrientes como o cálcio e magnésio permanecem em níveis satisfatórios. Em conseqüência, a saturação por bases dificilmente é inferior a $50 \%$. O potássio permanece mais ou menos estável, em níveis adequados para manter a produtividade das pastagens. A matéria orgânica e o nitrogênio permanecem em níveis aceitáveis, apesar das periódicas queimadas. No entanto, os teores de fósforo $(P)$, a partir do quarto a quinto ano do estabelecimento das pastagens, declinam acentuadamente, até atingir níveis praticamente indetectáveis, como se verifica em pastagens com mais de dez anos de utilização. Tal situação perdura por três a cinco anos após o estabelecimento da pastagem. A partir daí, há um decréscimo na produtividade de forragem e incremento na comunidade de plantas invasoras, como consequência da incapacidade da planta forrageira em suprir bons rendimentos em baixos níveis de fertilidade do solo. Deste modo, a reposição de nutrientes, através da calagem e/ou adubação, é uma prática indispensável para a recuperação da capacidade produtiva das pastagens, com reflexos positivos e significativos na sua capacidade de suporte e, consequentemente, no desempenho animal.

Neste trabalho são revisados os efeitos da calagem e adubação sobre a produtividade, composição química e persistência das pastagens cultivadas na Amazônia.

\section{Nutrientes Limitantes}

Trabalhos realizados na Amazônia, com o objetivo de avaliar os efeitos da adição ou omissão de macro e micronutrientes na produção de diversas gramíneas ( $B$. decumbens, Brachiaria brizantha cv. Marandu, B. humidicola, Hyparrhenia rufa, Panicum maximum cv. Centenário e Paspalum atratum cv. 
Pojuca) e leguminosas forrageiras (Stylosanthes guianensis, Centrosema pubescens e Desmodium ovalifolium), consistentemente demonstraram que o $\mathrm{P}$ foi o nutriente mais limitante, cuja ausência na adubação completa proporcionou drásticas reduções no rendimento de forragem. Os efeitos de Potássio (K), Enxofre (S), calagem e micronutrientes foram menos acentuados (Tabela 1). Contudo, a aplicação de níveis mais altos de $\mathrm{P}\left(150 \mathrm{~kg}\right.$ de $\left.\mathrm{P}_{2} \mathrm{O}_{5} \cdot \mathrm{ha}^{-1}\right)$ implicou em sintomas de deficiência de $K$, sugerindo que, nesses casos, a adubação potássica possa ser necessária (Serrão et al., 1979). Italiano et al. (1982) e Azevedo \& Souza (1982) não evidenciaram efeitos significativos da aplicação de $\mathrm{K}, \mathrm{S}$, calcário e micronutrientes na produção de matéria seca (MS) de $P$. maximum. A calagem pode ser desnecessária nas condições de pastagens cultivadas, em áreas de floresta, face às modificações químicas prolongadas impostas aos seus solos pela queima.

Tabela 1. Produção relativa (\%) de forragem de gramíneas e leguminosas com adubação completa, completa menos um nutriente e sem adubação, em áreas de pastagens da Amazônia.

\begin{tabular}{||l||ccccccc||}
\hline \multicolumn{1}{|c|}{ Adubação } & $\begin{array}{c}\text { Brachiaria } \\
\text { decumbens }\end{array}$ & $\begin{array}{c}\text { Brachiaria } \\
\text { brizantha }\end{array}$ & $\begin{array}{c}\text { Brachiaria } \\
\text { humidicola }\end{array}$ & $\begin{array}{c}\text { Hyparrhenia } \\
\text { rufa }\end{array}$ & $\begin{array}{c}\text { Panicum } \\
\text { maximum }\end{array}$ & $\begin{array}{c}\text { Paspalum } \\
\text { atratum }\end{array}$ & Leguminosas \\
\hline \hline Completo (C) & 100 & 100 & 100 & 100 & 100 & 100 & 100 \\
C - P & 47 & 48 & 56 & 45 & 16 & 22 & 55 \\
C - K & 70 & 42 & 74 & 84 & 59 & 54 & 60 \\
C - S & 62 & 68 & 84 & 53 & 37 & 44 & 77 \\
C - Calcário & 75 & 70 & 95 & 72 & 63 & 75 & 79 \\
C - FTE BR-12 & 73 & 77 & 92 & 67 & 96 & 90 & 59 \\
Testemunha & 54 & 17 & 70 & 44 & 15 & 20 & 46 \\
\hline
\end{tabular}

Fontes: Costa et al. (1989c,f; 1997a; 1998a; 2003; 2004), Costa \& Paulino (2001), Gonçalves et al. (1990a,b); Townsend et al. (2003).

* Completo $=\mathrm{P}+\mathrm{K}+\mathrm{S}+$ Calcário + FTE BR-12.

$\mathrm{P}=100 \mathrm{~kg}$ de $\mathrm{P}_{2} \mathrm{O}_{5} \cdot \mathrm{ha}^{-1}$ (superfosfato triplo).

$\mathrm{K}=100 \mathrm{~kg}_{\text {de }} \mathrm{K}_{2} \mathrm{O} \cdot \mathrm{ha}^{-1}$ (cloreto de potássio).

$\mathrm{S}=50 \mathrm{~kg}$ de $\mathrm{S} . \mathrm{ha}^{-1}$ (enxofre elementar).

Calcário $=1.000 \mathrm{~kg}$ de calcário dolomítico $\cdot$ ha $^{-1}(\mathrm{PRNT}=100 \%)$.

FTE BR-12 = $30 \mathrm{~kg}^{-h^{-1}}$ (mistura comercial de micronutrientes).

A remoção de nutrientes, via produtos animais, é relativamente pequena, quando comparada ao estoque disponível no ecossistema de pastagem. Salinas (1987) constatou que para uma produção de $504 \mathrm{~kg}$ de peso vivo.ha-1.ano-1, os nutrientes mais exportados foram o Cálcio (Ca) $\left(5,56 \mathrm{~kg} \cdot \mathrm{ha}^{-1}\right.$.ano-1 $) ; P(3,28$ 
$\left.\mathrm{kg} \cdot \mathrm{ha}^{-1} \cdot \mathrm{ano}^{-1}\right)$ e $\circ \mathrm{K}\left(1,11 \mathrm{~kg} \cdot \mathrm{ha}^{-1} \cdot \mathrm{ano}^{-1}\right)$, enquanto que a retirada do $\mathrm{S}(0,76$ $\mathrm{kg} \cdot \mathrm{ha}^{-1}$.ano-1) e do magnésio ( $\left.\mathrm{Mg}\right)\left(0,22 \mathrm{~kg} \cdot \mathrm{ha}^{-1} \cdot \mathrm{ano}^{-1}\right)$ foram de baixa magnitude. Logo, a adoção de práticas de manejo que envolva a utilização de germoplasma forrageiro com baixo requerimento nutricional, além de sistemas e pressões de pastejo compatíveis com a manutenção do equilíbrio do sistema soloplanta-animal, pode ser considerada como a chave para assegurar a produtividade das pastagens cultivadas, por longos períodos de tempo, nas áreas de floresta da região Amazônica.

\section{Fósforo (P)}

Nas gramíneas, o principal efeito do $\mathrm{P}$ consiste no aumento da produção de forragem, pois atua positivamente no desenvolvimento radicular, no crescimento e na divisão celular; contudo, os teores de proteína bruta (PB) e de outros nutrientes ( $\mathrm{K}, \mathrm{Ca}$ e $\mathrm{Mg}$ ), geralmente, são pouco afetados. Nas leguminosas, além de maximizar os rendimentos de forragem, devido ao melhor desenvolvimento radicular, favorecimento da nodulação e aumento da eficiência dos processos metabólicos, observa-se um incremento do teor de $\mathrm{N}$ da parte aérea, o que pode se refletir em melhor desempenho animal, já que, em geral, verifica-se uma maior percentagem de leguminosas na dieta selecionada pelos animais. Os teores totais de $\mathrm{P}$ nos solos tropicais é bastante variável - desde 200 até $600 \mathrm{mg} \cdot \mathrm{kg}^{-1}$. No entanto, os níveis de P disponível para o estabelecimento e crescimento das plantas forrageiras são muito baixos ( $<5 \mathrm{mg} \cdot \mathrm{kg}^{-1}$, Bray II). Isto se deve ao fato de que a maior parte do $\mathrm{P}$ presente no solo está na forma orgânica e em combinação com óxidos de ferro ( $\mathrm{Fe}$ ) e $\mathrm{Al}$, os quais apresentam baixa solubilidade, aumentando consideravelmente a capacidade de fixação do $\mathrm{P}$, especialmente quando se utilizam fontes mais solúveis (Fenster \& León, 1978). A disponibilidade de P é máxima entre valores de $\mathrm{pH} 5,5$ a 7,0. Quanto maior o teor de argila do solo, menor será a disponibilidade de $\mathrm{P}$ a curto prazo, em decorrência de sua maior fixação. Solos 
com alto percentual de argila caolinítica (tipo $1: 1$ ) retêm mais $\mathrm{P}$ que solos com argilas do tipo 2:1 (montmorilonita).

A movimentação do $\mathrm{P}$ até as raízes ocorre por difusão, mecanismo que é afetado pelo teor de umidade do solo, logo, à medida que este aumenta até níveis ótimos, o P torna-se mais disponível para as plantas. Em um Latossolo Amarelo, textura argilosa, fase floresta, na ausência de calagem, Costa et al. (1989e) constataram um incremento de $0,0623 \mathrm{mg}$ de $P$ disponível. $\mathrm{kg}^{-1}$ de solo, para cada kg de P.ha-1 adicionado. Com a aplicação de até $132 \mathrm{~kg}$ de P. ha-1 ${ }^{-1}$ a relação foi linear, sendo descrita pela equação $Y=2,63+0,0623 X$ $\left(r^{2}=0,97^{* *}\right)$. Para um Podzólico Vermelho-Amarelo, textura média, a aplicação de $1 \mathrm{~kg}$ de $\mathrm{P} \cdot \mathrm{ha}^{-1}$ resultou num acréscimo de 0,105 mg de P. $\mathrm{kg}^{-1}$ de solo (Costa, 1996).

As plantas forrageiras apresentam grandes variações quanto aos seus requerimentos por $\mathrm{P}$. A identificação daquelas espécies menos exigentes ou mais eficientes na absorção de $\mathrm{P}$ pode ser uma alternativa para assegurar a produtividade das pastagens cultivadas, por longos períodos de tempo. Segundo Salinas (1987), as principais características que determinam a tolerância a baixos níveis de $\mathrm{P}$ ou a maior eficiência em sua absorção $\mathrm{e}$ utilização seriam a extensão do sistema radicular; a exudação de substâncias que alteram o pH da rizosfera; a colonização das raízes por micorrizas arbusculares; as maiores taxas de absorção e translocação do $\mathrm{P}$ e, a tolerância as altas concentrações de alumínio presentes no solo. Costa (1989), avaliando o efeito da adubação fosfatada $\left(0,50\right.$ e $100 \mathrm{~kg}$ de $\left.\mathrm{P}_{2} \mathrm{O}_{5} \cdot \mathrm{ha}^{-1}\right)$, em oito gramíneas forrageiras, observou que Andropogon gayanus cv. Planaltina, $P$. maximum cvs. Comum e Tobiatã e $B$. humidicola foram as que apresentaram maior eficiência de absorção de $\mathrm{P}$ e, conseqüentemente, na produção de forragem (Tabela 2). Para cinco genótipos de A. gayanus, Costa \& Townsend (1996) constataram diferenças significativas na absorção de P. Para todos os 
Costa, N.L., Paulino, V.T., Townsend, C.R. et a. Calagem e adubação de pastagens na Amazônia. PUBVET, Londrina, V. 2, N. 43, Art\#413, Out5, 2008.

genótipos avaliados, a eficiência de utilização de $P$ foi inversamente proporcional às doses aplicadas (Tabela 3 ).

Tabela 2. Absorção de $\mathrm{P}\left(\mathrm{kg} \cdot \mathrm{ha}^{-1}\right)$ de gramíneas forrageiras tropicais, em função da adubação fosfatada.

\begin{tabular}{|l|ccc||}
\hline \multicolumn{1}{|c|}{ Gramíneas } & \multicolumn{3}{c|}{${\text { Doses de P }\left(\mathbf{k g} \cdot \mathbf{h a} \mathbf{-}^{-\mathbf{1}}\right)}$} \\
\cline { 2 - 4 } A. gayanus cv. Planaltina & $\mathbf{0}$ & $\mathbf{5 0}$ & $\mathbf{1 0 0}$ \\
B. humidicola & $7,84 \mathrm{~b}$ & $11,91 \mathrm{a}$ & $15,70 \mathrm{a}$ \\
B. decumbens & $8,91 \mathrm{a}$ & $9,82 \mathrm{bc}$ & $14,16 \mathrm{~b}$ \\
B. ruziziensis & $4,34 \mathrm{~d}$ & $6,75 \mathrm{e}$ & $9,30 \mathrm{de}$ \\
P. maximum cv. Comum & $3,15 \mathrm{~d}$ & $6,27 \mathrm{e}$ & $8,91 \mathrm{e}$ \\
P. maximum cv. Tobiatã & $7,80 \mathrm{~b}$ & $9,55 \mathrm{C}$ & $12,78 \mathrm{c}$ \\
S. sphacelata cv. Nandi & $9,52 \mathrm{a}$ & $10,76 \mathrm{~b}$ & $13,05 \mathrm{bc}$ \\
S. sphacelata cv. Kazungula & $5,87 \mathrm{c}$ & $7,53 \mathrm{~d}$ & $9,79 \mathrm{de}$ \\
\hline
\end{tabular}

- Médias seguidas de mesma letra, na coluna, não diferem entre si $(P>0,05)$ pelo teste de Tukey.

Fonte: Costa (1989).

Tabela 3. Absorção e eficiência de utilização de $\mathrm{P}$ de genóripos de $A$. gayanus, em função da adubação fosfatada.

\begin{tabular}{|c|c|c|c|c|c|c|}
\hline \multirow{3}{*}{ Genótipos } & \multicolumn{6}{|c|}{ Doses de P (kg.ha-1) } \\
\hline & $\mathbf{0}$ & 50 & 100 & $\mathbf{0}$ & 50 & 100 \\
\hline & \multicolumn{3}{|c|}{ Absorção de $\mathrm{P}\left(\mathrm{kg} \cdot \mathrm{ha}^{-1}\right)^{1}$} & \multicolumn{3}{|c|}{ 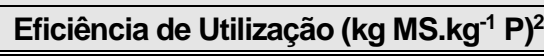 } \\
\hline A. gayanus cv. Planaltina & $11,37 b$ & $15,27 b$ & $21,43 c$ & $813 \mathrm{~A}$ & $730 \mathrm{~B}$ & $658 \mathrm{~B}$ \\
\hline A. gayanus CPAC-3083 & $6,88 \mathrm{e}$ & $9,03 \mathrm{~d}$ & $14,83 \mathrm{e}$ & $878 \mathrm{~A}$ & $787 \mathrm{~B}$ & $625 \mathrm{C}$ \\
\hline A. gayanus CPAC-3084 & $10,52 d$ & $13,20 \mathrm{c}$ & $17,20 d$ & $781 \mathrm{~A}$ & $704 \mathrm{~B}$ & $671 \mathrm{~B}$ \\
\hline A. gayanus CPAC-3085 & $11,92 \mathrm{c}$ & $18,47 \mathrm{a}$ & $23,40 \mathrm{~b}$ & $909 \mathrm{~A}$ & $741 \mathrm{~B}$ & $709 \mathrm{~B}$ \\
\hline A. gayanus CPAC-3086 & $13,63 \mathrm{a}$ & $18,63 \mathrm{a}$ & $25,14 a$ & $854 \mathrm{~A}$ & $800 \mathrm{AB}$ & 724 B \\
\hline A. gayanus CPAC-3087 & $10,34 d$ & $9,17 \mathrm{~d}$ & $12,61 \mathrm{f}$ & $577 \mathrm{~B}$ & $769 \mathrm{~A}$ & $694 \mathrm{AB}$ \\
\hline
\end{tabular}

${ }^{1}$ Médias seguidas de mesma letra, na coluna, não diferem entre si $(P>0,05)$ pelo teste de Tukey

${ }^{2}$ Médias seguidas de mesma letra, na linha, não diferem entre si $(P>0,05)$ pelo teste de Tukey

Fonte: Costa \& Townsend (1996)

O conhecimento dos níveis críticos internos (NCI) é muito importante para diagnosticar o estado nutricional ou o estabelecimento da necessidade de adubação fosfatada. O NCI indica o teor de P no tecido vegetal abaixo do qual há probabilidade de respostas significativas à adição do nutriente ao solo. Para as condições edáficas de Rondônia foram determinados os NCI para as 
Costa, N.L., Paulino, V.T., Townsend, C.R. et a. Calagem e adubação de pastagens na Amazônia. PUBVET, Londrina, V. 2, N. 43, Art\#413, Out5, 2008.

principais gramíneas e leguminosas forrageiras utilizadas na formação e/ou recuperação de pastagens (Tabela 4).

Tabela 4. Níveis críticos internos de fósforo de gramíneas e leguminosas forrageiras.

\begin{tabular}{|l||c|c|}
\hline \multicolumn{1}{|c||}{ Espécies } & Nível Crítico Interno (g.kg $^{-1}$ ) & Dose de P Aplicada (kg.ha-1 $)$ \\
\hline \hline Gramíneas & & \\
A. gayanus cv. Planaltina & 1,35 & 57,8 \\
B. brizantha cv. Marandu & 1,71 & 111,8 \\
B. brizantha cv. Xaraés & 1,27 & 112,8 \\
B. decumbens & 1,47 & 138,2 \\
B. dictyoneura & 1,39 & 95,6 \\
B. humidicola & 1,40 & 54,8 \\
P. atratum cv. Pojuca & 1,53 & 109,6 \\
P. maximum cv. Centenário & 1,78 & 162,4 \\
P. maximum cv. Massai & 2,27 & 170,0 \\
P. maximum cv. Mombaça & 2,78 & 211,0 \\
P. maximum cv. Tobiatã & 2,38 & 189,2 \\
P. purpureum cv. Cameroon & 1,97 & 176,4 \\
\hline Leguminosas & & \\
A. angustissima & 1,69 & 127,6 \\
A. pintoi cv. Amarillo & 2,00 & 148,0 \\
C. acutifolium ClAT-5277 & 1,58 & 13,2 \\
C. cajan & 3,31 & 237,0 \\
D. ovalifolium & 1,69 & 134,6 \\
L. leucocephala & 3,87 & 279,0 \\
P. phaseoloides & 1,71 & 148,0 \\
\hline \hline
\end{tabular}

Fontes: Costa (1996a); Costa et al. (2004).

A determinação dos níveis adequados para a adubação fosfatada de pastagens, tem sido objetivo de diversos experimentos conduzidos na Amazônia. Para pastagens de $B$. humidicola e $A$. gayanus cv. Planaltina, estabelecidas em solos sob cerrados, foram obtidos incrementos na produção de MS de 32,7 e 87,5\%, respectivamente, com a aplicação de $100 \mathrm{~kg}$ de $\mathrm{P}_{2} \mathrm{O}_{5}$. ha-1 (Costa et al., 1989a; 1990b). Em um Latossolo Amarelo, textura média, fase floresta, Costa et al. (2004) estimaram em 112; 169; 141; 127 e 176 mg de P. $\left(\mathrm{dm}^{3}\right)^{-1}$, respectivamente para $B$. brizantha cv. Xaraés, $P$. maximum cv. Massai, $P$. 
phaseoloides, D. ovalifolium e P. purpureum cv. Cameroon, as doses de máxima eficiência técnica (DMET).

Para a adubação de pastagens de $A$. gayanus cv. Planaltina, $B$. decumbens, $B$. dictyoneura, B. humidicola e H. rufa, Costa et al. (1989f) e Gonçalves et al. $(1990 \mathrm{a}, \mathrm{b})$ sugerem como alternativa viável, doses entre 50 e $80 \mathrm{~kg}$ de $\mathrm{P}_{2} \mathrm{O}_{5} /$ ha-1 $^{-1}$ a qual pode ser realizada, a lanço, após o rebaixamento da vegetação através da roçagem ou pela utilização de altas pressões de pastejo. Para C. cajan, a aplicação de $50 \mathrm{~kg}$ de $\mathrm{P}_{2} \mathrm{O}_{5}$.ha-1 ${ }^{-1}$ resultou num incremento de $38,3 \%$ na produção de forragem comestível, além de promover efeitos positivos em sua qualidade, notadamente nos conteúdos de nitrogênio (N) e $P$, como decorrência de sua melhor nodulação (Costa et al., 1990a). Para A. angustissima, Costa \& Paulino (1999a) constataram acréscimos nos rendimentos de MS de 150 e $228 \%$, respectivamente para a aplicação de 50 e $100 \mathrm{~kg}$ de P.ha-1. Em pastagens de B. brizantha, Costa et al. (2004) estimaram em 221,7 kg de $\mathrm{P}_{2} \mathrm{O}_{2}$.ha-1 a DMET e o $\mathrm{NCI}$, relacionado com $80 \%$ do rendimento máximo de forragem, em $1,71 \mathrm{~g}$ de P. $\mathrm{kg}^{-1}$ (Tabela 5).

Tabela 5. Rendimento de matéria seca (MS), eficiência de utilização de fósforo (EUP), teores e quantidades absorvidas de nitrogênio e fósforo por $B$. brizantha $\mathrm{cv}$. Marandu, em função da adubação fosfatada.

\begin{tabular}{|c|c|c|c|c|c|c|}
\hline \multirow{2}{*}{ 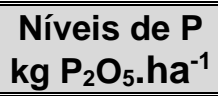 } & \multirow{2}{*}{$\begin{array}{l}\text { MS }^{1} \\
\text { t.ha }\end{array}$} & \multirow{2}{*}{$\begin{array}{c}\text { EUP } \\
\text { kg MS. } \text { g }^{-1} P\end{array}$} & \multicolumn{2}{|c|}{ Nitrogênio } & \multicolumn{2}{|c|}{ Fósforo } \\
\hline & & & g. $\mathbf{k g}^{-1}$ & kg.ha-1 & g. kg $^{-1}$ & kg.ha" \\
\hline 0 & $4,38 \mathrm{f}$ & $0,93 a$ & $14,76 \mathrm{a}$ & $64,6 \mathrm{e}$ & $1,07 \mathrm{f}$ & $4,69 \mathrm{f}$ \\
\hline 50 & $7,13 \mathrm{e}$ & $0,80 a$ & $15,70 \mathrm{a}$ & $111,9 d$ & $1,25 \mathrm{e}$ & $8,91 \in$ \\
\hline 100 & $9,28 d$ & $0,69 \mathrm{~b}$ & $15,31 \mathrm{a}$ & $142,1 \mathrm{c}$ & $1,44 d$ & $13,36 \mathrm{c}$ \\
\hline 150 & $11,70 \mathrm{c}$ & $0,64 b$ & 15,73 a & $184,0 \mathrm{~b}$ & $1,56 \mathrm{c}$ & $18,25 \mathrm{c}$ \\
\hline 200 & $13,22 \mathrm{~b}$ & $0,59 \mathrm{~b}$ & $14,98 \mathrm{a}$ & $198,0 \mathrm{a}$ & $1,68 b$ & $22,21 \mathrm{~b}$ \\
\hline 250 & $13,79 a b$ & $0,57 \mathrm{~b}$ & $14,70 \mathrm{a}$ & $202,7 \mathrm{a}$ & $1,73 a b$ & $23,85 \mathrm{~b}$ \\
\hline 300 & $14,67 \mathrm{a}$ & $0,55 \mathrm{~b}$ & $14,33 \mathrm{a}$ & $210,3 \mathrm{a}$ & $1,76 \mathrm{a}$ & $25,81 a$ \\
\hline
\end{tabular}

- Médias seguidas de mesma letra, na coluna, não diferem entre si $(P>0,05)$ pelo teste de Tukey.

1 Total de três cortes a intervalos de oito semanas.

Fonte: Costa et al. (2004). 


\subsection{Fosfatos naturais}

A utilização de fosfatos de rocha, como fonte de $\mathrm{P}$, surge como uma alternativa tecnicamente viável, considerando-se que sua eficiência agronômica, notadamente as taxas de dissolução, são estimuladas pela acidez do solo. Ademais, geralmente, estes apresentam menor custo unitário e maior efeito residual. Recomenda-se o uso combinado de fontes de $\mathrm{P}$ com alta e baixa solubilidade. Deste modo, a fonte mais solúvel forneceria no curto prazo, o $\mathrm{P}$ necessário para o rápido crescimento inicial, período crítico de competição com as plantas invasoras. A fonte menos solúvel (fosfato de rocha) liberaria o $\mathrm{P}$ paulatinamente, possibilitando maior persistência da pastagem. A eficiência agronômica dos fosfatos naturais depende, principalmente de suas características físicas e químicas e, sobretudo, da sua solubilidade. Todos os fosfatos naturais brasileiros são apatíticos, ou seja, há uma predominância de fosfatos de cálcio. $\mathrm{O}$ teor de $\mathrm{P}_{2} \mathrm{O}_{5}$ total dos concentrados fosfáticos varia de 23 a $40 \%$. Contudo, a solubilidade, avaliada por extratores tradicionais, é muito baixa quando comparada com a dos superfosfatos, termofosfatos e mesmo com a de alguns fosfatos naturais estrangeiros. Para que o $\mathrm{P}$ seja liberado da apatita torna-se necessário a reação entre o fosfato aplicado e o solo. A liberação de $P$ é proporcional à intensidade dessa reação e, por isso, é conveniente proporcionar o máximo de contacto entre as partículas do fosfato natural e o solo (Sanzonowicz \& Goedert, 1985). Deste modo, assumem grande importância o grau de moagem do fosfato, o modo de aplicação e a sua incorporação ao solo. Para fontes de baixa solubilidade recomenda-se a aplicação sob a forma de pó, o qual deve ser incorporado para se obter o máximo contacto com as partículas do solo (Costa, 1999).

A eficiência da utilização de fosfatos naturais está diretamente relacionada à capacidade da planta em absorver $\mathrm{P}$ do solo e utilizá-lo mais eficientemente em seu metabolismo. Em geral, a resposta das diversas espécies forrageiras depende da sua velocidade de crescimento, da sua exigência em $\mathrm{P}$ e da sua 
capacidade em desenvolver seu sistema radicular, principalmente em condições adversas do solo (Sanzonowicz \& Goedert, 1985). A resposta diferenciada à fertilização fosfatada determina o manejo mais adequado para cada planta forrageira. Em condições de elevada acidez, P. maximum cv. Makueni tem baixo desenvolvimento, mesmo em níveis elevados de P. Já, A. gayanus cv. Planaltina apresenta excelente adaptação aos solos ácidos, apesar de responder significativamente à calagem. Deste modo, $P$. maximum é uma espécie mais exigente em nutrientes, sendo recomendada para solos com baixa acidez e bem supridos em P. Uma fonte de P de baixa solubilidade, potencialmente, não seria eficiente para esta espécie, ocorrendo o inverso quanto ao A. gayanus (Salinas, 1987; Costa, 1999).

Para pastagens de $A$. gayanus cv. Planaltina, B. brizantha cv. Marandu e $P$. atratum cv. Pojuca, a aplicação de $200 \mathrm{~kg} \cdot \mathrm{ha}^{-1}$ de $\mathrm{P}_{2} \mathrm{O}_{5}$, sob a forma de Super Fosfato Triplo (SFT) ou termofosfato de Yoorin (TY) $\left(\mathrm{P}_{2} \mathrm{O}_{5}\right.$ total $=18,0 \% ; \mathrm{P}_{2} \mathrm{O}_{5}$ solúvel em ácido cítrico $=16,5 \%$ ) resultou em maiores rendimentos de forragem e quantidades absorvidas de $\mathrm{P}$, enquanto que para os fosfatos naturais de Patos de Minas (FNPM) $\left(\mathrm{P}_{2} \mathrm{O}_{5}\right.$ total $=24 \% ; \mathrm{P}_{2} \mathrm{O}_{5}$ solúvel em ácido cítrico $=3,8 \%)$ e Olinda $(\mathrm{FNO})\left(\mathrm{P}_{2} \mathrm{O}_{5}\right.$ total $=26 \% ; \mathrm{P}_{2} \mathrm{O}_{5}$ solúvel em ácido cítrico $=5,3 \%$ ) não se observou efeito significativo de doses (100 ou $200 \mathrm{~kg}$ de $\mathrm{P}_{2} \mathrm{O}_{5}$. ha- ${ }^{-1}$ ). O SFT e o TY foram as fontes que apresentaram maiores índices de eficiência agronômica, seguindo-se FNO e Araxá (FNA) $\left(\mathrm{P}_{2} \mathrm{O}_{5}\right.$ total $=36 \% ; \mathrm{P}_{2} \mathrm{O}_{5}$ solúvel em ácido cítrico $=4,5 \%)$, ficando o de Patos de Minas com a menor eficiência agronômica (Costa, 1996a; Costa et al., 1993, 2004). Para A. angustissima e L. leucocephala, a utilização de $100 \mathrm{~kg}$ de $\mathrm{P}_{2} \mathrm{O}_{5}$.ha-1 ${ }^{-1}$, sob a forma de FNA ou FNO proporcionou incrementos superiores a $100 \%$ no rendimento de MS, número e peso de nódulos (Costa \& Paulino, 1993; 1999a). Costa et al. (2003), em pastagens de B. humidicola, verificaram que a fertilização fosfatada, independentemente da fonte utilizada, incrementou significativamente os rendimentos de forragem da gramínea, contudo não afetou os teores de P. O SFT e o TY foram as fontes mais eficientes, 
Costa, N.L., Paulino, V.T., Townsend, C.R. et a. Calagem e adubação de pastagens na Amazônia. PUBVET, Londrina, V. 2, N. 43, Art\#413, Out5, 2008.

seguindo-se FNA e FNO, ficando o FNPM com a menor eficiência agronômica (Tabela 6).

Tabela 6. Rendimento de matéria seca (MS), teores e quantidades absorvidas de fósforo por Brachiaria humidicola e Índice de Eficiência Agronômica, em função da aplicação de fontes e doses de fósforo.

\begin{tabular}{|c|c|c|c|c|c|}
\hline \multirow{2}{*}{ Fontes de Fósforo } & \multirow{2}{*}{$\begin{array}{c}\text { Doses } \\
\left(\mathrm{kg} \mathrm{P}_{2} \mathrm{O}_{5} \cdot \mathrm{ha}^{-1}\right)\end{array}$} & \multirow{2}{*}{$\begin{array}{c}\text { MS } \\
\left(\text { t.ha-1 }^{-1}\right)^{1}\end{array}$} & \multicolumn{2}{|c|}{ Fósforo } & \multirow{2}{*}{$\begin{array}{l}\text { IEA' } \\
(\%)\end{array}$} \\
\hline & & & g.kg-1 & kg.ha $^{-1}$ & \\
\hline Testemunha & 0 & $6,13 \mathrm{e}$ & $1,10 \mathrm{a}$ & $6,74 \mathrm{~g}$ & -- \\
\hline \multirow[t]{2}{*}{ Superfosfato triplo } & 100 & 11,08 b & $1,34 \mathrm{a}$ & $14,85 \mathrm{bc}$ & 100 \\
\hline & 200 & $15,29 \mathrm{a}$ & $1,30 \mathrm{a}$ & $19,88 a$ & 100 \\
\hline \multirow[t]{2}{*}{ Termofosfato Yoorin } & 100 & 10,22 bc & $1,25 \mathrm{a}$ & $12,78 \mathrm{~cd}$ & 82 \\
\hline & 200 & 13,88 a & $1,17 \mathrm{a}$ & $16,24 b$ & 85 \\
\hline \multirow[t]{2}{*}{ Fosfato Natural Patos de Minas } & 100 & 7,44 de & $1,25 a$ & $9,30 \mathrm{fg}$ & 26 \\
\hline & 200 & $8,75 \mathrm{bcd}$ & $1,21 \mathrm{a}$ & $10,59 \mathrm{def}$ & 29 \\
\hline \multirow[t]{2}{*}{ Fosfato Natural de Olinda } & 100 & $7,50 \mathrm{de}$ & $1,33 a$ & 9,98 def & 30 \\
\hline & 200 & $9,21 \mathrm{bcd}$ & $1,28 \mathrm{a}$ & 11,79 def & 34 \\
\hline \multirow[t]{2}{*}{ Fosfato Natural de Araxá } & 100 & 8,10 cde & $1,19 a$ & 9,64 efg & 43 \\
\hline & 200 & $10,28 \mathrm{bc}$ & $1,22 \mathrm{a}$ & $12,54 \mathrm{~cd}$ & 45 \\
\hline
\end{tabular}

- Médias seguidas de mesma letra, na coluna, não diferem entre si $(P>0,05)$ pelo teste de Tukey.

1 Totais de oito cortes a intervalos de seis semanas.

${ }^{2}$ IEA $=Y_{2}-Y_{1} / Y_{3}-Y_{1} \times 100$, onde $Y_{1}=$ produção da testemunha; $Y_{2}=$ produção da fonte testada na dose a e, $Y_{3}=$ produção da fonte referência (superfosfato triplo) na dose $a$.

Fonte: Costa et al. (2003).

\subsection{Micorrizas arbusculares (MA)}

As MA são associações simbióticas entre as raízes da maioria das plantas superiores e certos fungos de solo, sendo caracterizada pelo íntimo contacto entre os simbiontes, pela perfeita integração morfológica e funcional, além da troca simultânea de metabólitos e nutrientes. A colonização das raízes por MA resulta em modificações na fisiologia, bioquímica e nutrição mineral da planta hospedeira, especialmente no favorecimento da absorção, translocação e utilização de nutrientes e água. Em geral, os efeitos das MA sobre o crescimento das plantas se manifestam pela atuação de um ou vários mecanismos, tais como: aumento da superfície de absorção de nutrientes; maior longevidade das raízes absorventes; melhor utilização de formas de 
nutrientes pouco disponíveis para as plantas não colonizadas; alterações na relação água-solo-planta; redução dos efeitos adversos do $\mathrm{pH}$ e da toxicidade de alumínio; aumento na nodulação e capacidade de fixação de $\mathrm{N}$ atmosférico; melhor desenvolvimento de bactérias solubilizadoras de $\mathrm{P}$ na micorrizosfera e aumento na produção de fitohormônios (Lopes et al. 1983; Zambolim \& Siqueira, 1985).

Nos solos de baixa fertilidade natural, notadamente naqueles deficientes em $\mathrm{P}$, as associações com MA apresentam efeitos benéficos mais acentuados (Costa et al., 1989b,d; 1995a,b). Rhodes \& Gerdemann (1975) observaram que plantas colonizadas absorviam ${ }^{32} \mathrm{p}$ colocado até $8 \mathrm{~cm}$ de distância da superfície da raiz, devido às hifas externas do fungo funcionarem como extensão do sistema radicular, podendo absorver nutrientes além da zona dos pêlos radiculares e da zona de depleção ( 1 a $2 \mathrm{~mm}$ ) que se desenvolve ao redor das raízes. Cress et al. (1979) verificaram que as raízes colonizadas por MA possuiam um sistema de absorção de $\mathrm{P}$ altamente eficiente, caracterizado por alto valor Vmax (velocidade máxima de absorção) e baixo $K_{m}$ (constante de Michaelis-Menten = concentração de $\mathrm{P}$ na qual se obtém a metade de Vmax), para plantas crescendo em baixos níveis de P disponível. Howeler et al. (1982) relacionando a produção de MS obtida pela mandioca com o $\mathrm{P}$ disponível no solo, observaram níveis críticos de 190 e $15 \mathrm{mg}^{\mathrm{kg}}{ }^{-1}$ de $\mathrm{P}$ (Bray II), respectivamente para plantas não inoculadas e inoculadas por MA. Costa \& Paulino (1989, 1991) demonstraram que a inoculação de Scutellospora heterogama e Gigaspora margarita em A. gayanus cv. Planaltina e, S. heterogama em Stylosanthes capitata cv. Capica proporcionou rendimentos de MS semelhantes ou superiores aos obtidos com a aplicação de $50 \mathrm{~kg}$ de $\mathrm{P}_{2} \mathrm{O}_{5}$. ha-1 ${ }^{-1}$, na ausência de inoculação. Ademais, as absorções de $\mathrm{N}$ e $\mathrm{P}$ foram incrementadas com a inoculação de MA (Tabela 7). 
Tabela 7. Rendimento de matéria seca (MS) e quantidades absorvidas de fósforo e nitrogênio por A. gayanus cv. Planaltina e $S$. capitata cv. Capica, em função da adubação fosfatada e da inoculação de micorrizas arbusculares.

\begin{tabular}{|c|c|c|c|c|c|c|}
\hline \multirow[b]{2}{*}{ Tratamentos } & \multicolumn{3}{|c|}{ A. gayanus } & \multicolumn{3}{|c|}{ S. capitata } \\
\hline & $\begin{array}{c}\text { MS } \\
\text { (g.vaso- })\end{array}$ & $\begin{array}{c}\text { Fósforo } \\
\left(\text { mg.vaso- }^{-1}\right)\end{array}$ & $\begin{array}{l}\text { Nitrogênio } \\
\left.\text { (mg.vaso- }^{-1}\right)\end{array}$ & $\begin{array}{c}\text { MS } \\
\text { (g.vaso-1) }\end{array}$ & $\begin{array}{c}\text { Fósforo } \\
\text { (mg.vaso-1) }\end{array}$ & $\begin{array}{l}\text { Nitrogênio } \\
\text { (mq.vaso-1) }^{-1}\end{array}$ \\
\hline Testemunha & $3,92 \mathrm{c}$ & $4,98 \mathrm{c}$ & $65,8 d$ & $4,23 d$ & $4,94 \mathrm{e}$ & $109,1 \mathrm{c}$ \\
\hline Acaulospora muricata & $6,05 b$ & $10,83 b$ & $113,1 c$ & $6,48 \mathrm{c}$ & $10,82 d$ & $325,3 \mathrm{a}$ \\
\hline Gigaspora margarita & $7,14 \mathrm{a}$ & $11,49 a$ & $156,3 \mathrm{a}$ & $8,56 \mathrm{~b}$ & $13,78 \mathrm{c}$ & $241,1 \mathrm{~b}$ \\
\hline Scutellospora heterogama & $6,81 \mathrm{ab}$ & $11,58 \mathrm{a}$ & $139,6 \mathrm{~b}$ & $9,85 a$ & $16,74 \mathrm{~b}$ & $330,0 \mathrm{a}$ \\
\hline $50 \mathrm{~kg}$ de $\mathrm{P}_{2} \mathrm{O}_{5} \cdot \mathrm{ha}^{-1}$ & $5,83 b$ & $10,61 \mathrm{~b}$ & $105,5 \mathrm{c}$ & $10,89 a$ & 20,26 a & 338,7 a \\
\hline
\end{tabular}

- Médias seguidas de mesma letra, na coluna, não diferem entre si $(P>0,05)$ pelo teste de Tukey.

Fonte: Costa \& Paulino (1989, 1991).

Os efeitos positivos da micorrização sobre o crescimento e absorção de $\mathrm{P}$ em gramíneas e leguminosas forrageiras tropicais estão amplamente documentados (Costa, 1996b; Costa et al., 1989d, 1990c). No entanto, as respostas estão condicionadas às interrelações entre características do solo, espécies de plantas forrageiras e de fungos micorrízicos. Costa \& Paulino (1990), avaliando os efeitos da inoculação de Gigaspora margarita em seis gramíneas e 11 leguminosas forrageiras, verificaram acréscimos superiores a $100 \%$ nos rendimentos de MS e na absorção de $P$, sendo as espécies mais responsivas $L$. leucocephala, D. ovalifolium CIAT-350, P. phaseoloides CIAT9900, A. gayanus cv. Planaltina e $P$. guenoarum FCAP-43. Costa \& Paulino (1991, 1997, 1999b) verificaram que as espécies de MA mais efetivas, em termos de produção de MS e absorção de $\mathrm{P}$, foram Scutellospora heterogama, Gigaspora margarita e Glomus macrocarpum para A. gayanus cv. Planaltina e, Acaulospora muricata para B. brizantha cv. Marandu e B. humidicola (Tabela 8). Costa et al. (1997b) e Costa \& Paulino (1999e) selecionaram A. muricata e E. colombiana e, G. margarita, S. heterogama e A. muricata, respectivamente para inoculação em $A$. angustissima e $P$. phaseoloides, como as espécies de MA mais eficientes, em termos de produção de MS, absorção de $\mathrm{P}$ e peso seco de nódulos (Tabela 9). O melhoramento da fertilidade do solo através da aplicação de fosfatos naturais potencializa os efeitos das MA. Segundo Barea et 
al. (1975) as plantas colonizadas, por apresentarem menores valores de $\mathrm{K}_{\mathrm{m}}$, são capazes de baixar o nível de $\mathrm{P}$ na solução para valores inferiores aos do produto de solubilidade de compostos pouco solúveis. Deste modo, as MA ao aumentarem a absorção de $\mathrm{P}$ solúvel, estimulam a dissociação química do fosfato para manter o seu equilíbrio na solução do solo (Barea \& Ázcon-Aguilar, 1983).

Tabela 8. Rendimento de matéria seca (MS) e quantidades absorvidas de $\mathrm{P}$ de gramíneas forrageiras, em função da inoculação de micorrizas arbusculares.

\begin{tabular}{|c|c|c|c|c|c|c|}
\hline \multirow[b]{2}{*}{ Tratamentos } & \multicolumn{2}{|c|}{ A. gayanus } & \multicolumn{2}{|c|}{ B. brizantha } & \multicolumn{2}{|c|}{ B. humidicola } \\
\hline & $\begin{array}{c}\text { MS } \\
\left.\text { (g.vaso-1) }^{-1}\right)\end{array}$ & $\underset{\text { (mg.vaso }}{\stackrel{\text { P }}{\text { P }})}$ & $\begin{array}{c}\text { MS } \\
\text { (g.vaso-1) }\end{array}$ & $\underset{\substack{\text { (mg.vaso- } \\
\text { 1) }}}{\mathbf{P}}$ & $\begin{array}{c}\text { MS } \\
\left(\text { g.vaso- }^{-1}\right)\end{array}$ & $\begin{array}{c}\mathrm{P} \\
\text { (mg.vaso }^{-1} \text { ) }\end{array}$ \\
\hline Testemunha & $2,76 f$ & $2,65 \mathrm{e}$ & $1,37 f$ & $1,26 f$ & $2,49 f$ & $2,71 \mathrm{e}$ \\
\hline Acaulospora laevis & $6,24 \mathrm{bcd}$ & $7,49 \mathrm{bc}$ & $4,93 \mathrm{bc}$ & $4,83 \mathrm{~cd}$ & $6,91 \mathrm{~b}$ & $8,36 \mathrm{a}$ \\
\hline A. muricata & $5,13 \mathrm{de}$ & $6,25 \mathrm{~cd}$ & $6,20 a$ & $7,38 \mathrm{a}$ & $7,12 \mathrm{a}$ & $8,76 \mathrm{a}$ \\
\hline Gigaspora margarita & $7,28 \mathrm{ab}$ & $8,59 \mathrm{ab}$ & $5,11 \mathrm{bc}$ & $5,98 \mathrm{bc}$ & $5,41 \mathrm{c}$ & $6,87 \mathrm{~b}$ \\
\hline Glomus etunicatum & $6,10 \mathrm{bcd}$ & 7,75 bc & $4,68 \mathrm{~cd}$ & $5,62 \mathrm{~cd}$ & $4,01 \mathrm{~d}$ & $5,01 \mathrm{c}$ \\
\hline G. mossaea & $4,69 \mathrm{e}$ & $5,21 d$ & $3,82 \mathrm{de}$ & $4,32 \mathrm{e}$ & $4,17 d$ & $4,92 \mathrm{c}$ \\
\hline G. fasciculatum & 5,95 cde & $7,79 a b c$ & $3,05 \mathrm{e}$ & $3,54 \mathrm{e}$ & 3,75 e & $4,24 d$ \\
\hline G. macrocarpum & $7,03 \mathrm{abc}$ & $8,64 \mathrm{ab}$ & $4,29 \mathrm{~cd}$ & $4,59 \mathrm{de}$ & $4,09 d$ & $4,66 \mathrm{~cd}$ \\
\hline Scutellospora heterogama & $8,33 \mathrm{a}$ & $9,66 \mathrm{a}$ & $5,77 \mathrm{ab}$ & $7,15 \mathrm{ab}$ & $6,80 \mathrm{~b}$ & $8,77 \mathrm{a}$ \\
\hline
\end{tabular}

- Médias seguidas de mesma letra, na coluna, não diferem entre si $(P>0,05)$ pelo teste de Tukey.

Fonte: Costa \& Paulino (1991, 1997, 1999b).

Tabela 9. Rendimento de matéria seca (MS), quantidades absorvidas de $\mathrm{P}$ e peso seco de nódulos de leguminosas forrageiras, em função da inoculação de micorrizas arbusculares.

\begin{tabular}{|c|c|c|c|c|c|c|}
\hline \multirow[b]{2}{*}{ Tratamentos } & \multicolumn{3}{|c|}{ A. angustissima } & \multicolumn{3}{|c|}{ P. phaseoloides } \\
\hline & $\begin{array}{c}\text { MS } \\
\text { (g.vaso- } \\
1 \text { ) } \\
\end{array}$ & $\begin{array}{c}\mathbf{P} \\
\text { (mg.vaso- } \\
1 \text { ) }\end{array}$ & $\begin{array}{c}\text { Nódulos } \\
\left(\text { mg.vaso- }^{-1}\right)\end{array}$ & $\begin{array}{c}\text { MS } \\
\left.\text { (g.vaso- }^{-1}\right) \\
\end{array}$ & $\begin{array}{c}\mathbf{P} \\
\text { (mg.vaso }^{-1} \text { ) } \\
\end{array}$ & $\begin{array}{c}\text { Nódulos } \\
\left.\text { (mg.vaso- }^{-1}\right)\end{array}$ \\
\hline Testemunha & $4,08 \mathrm{f}$ & $5,8 f$ & $0,75 \mathrm{~g}$ & $3,55 \mathrm{e}$ & $3,85 f$ & 0,54 \\
\hline Acaulospora laevis & 7,37 cde & $13,6 \mathrm{de}$ & $1,09 f$ & $8,05 \mathrm{~b}$ & $13,68 \mathrm{~b}$ & 0,97 \\
\hline A. muricata & $14,44 a b$ & $25,1 \mathrm{abc}$ & $1,71 \mathrm{a}$ & $9,12 a b$ & $13,92 b$ & 1,12 \\
\hline Entrophosphora colombiana & $15,87 \mathrm{a}$ & $26,9 \mathrm{a}$ & $1,61 \mathrm{ab}$ & --- & --- & --- \\
\hline Gigaspora margarita & $8,59 \mathrm{~cd}$ & $15,4 \mathrm{~cd}$ & $1,21 \mathrm{de}$ & $10,72 \mathrm{a}$ & $16,08 \mathrm{a}$ & 1,87 \\
\hline G. gigantea & $9,22 \mathrm{c}$ & $17,9 \mathrm{c}$ & $1,27 \mathrm{de}$ & --- & --- & --- \\
\hline Glomus etunicatum & 7,35 cde & 14,5 cde & 1,18 def & $5,40 d$ & 9,18 e & 1,40 \\
\hline G. fasciculatum & 5,49 ef & $11,2 \mathrm{e}$ & $1,37 \mathrm{~cd}$ & 7,72 bc & $11,58 \mathrm{c}$ & 1,27 \\
\hline G. mosseae & $6,14 \mathrm{e}$ & $11,8 \mathrm{de}$ & 1,01 ef & $4,91 \mathrm{~d}$ & 6,87 & 1,32 \\
\hline G. macrocarpum & $6,89 \mathrm{de}$ & $12,9 \mathrm{de}$ & $1,26 \mathrm{de}$ & $6,25 \mathrm{~cd}$ & $10,05 d$ & 1,21 \\
\hline Scutellospora heterogama & $12,16 \mathrm{~b}$ & $22,6 \mathrm{~b}$ & $1,48 \mathrm{bc}$ & $9,67 \mathrm{a}$ & $13,54 \mathrm{~b}$ & 1,99 \\
\hline
\end{tabular}


- Médias seguidas de mesma letra, na coluna, não diferem entre si $(P>0,05)$ pelo teste de Tukey.

Fonte: Costa et al. (1997b), Costa \& Paulino (1997, 1999e).

Para P. phaseoloides, Costa et al. (2004) constataram incrementos de 158 e $42 \%$ nos rendimentos de MS das plantas inoculadas com G. margarita e fertilizadas com $50 \mathrm{~kg}$ de $\mathrm{P}_{2} \mathrm{O}_{5} \cdot \mathrm{ha}^{-1}$, comparativamente àquelas apenas inoculadas com MA ou fertilizada com fosfato de rocha. Costa \& Paulino (1999c,d; 2001) verificaram que a inoculação de MA, simultaneamente com a aplicação de fosfato de rocha, promoveu acréscimos médios de 55,4 e 32,8\% nos rendimentos de MS, respectivamente, para A. gayanus e Sesbania sesban, em comparação com a aplicação isolada do fosfato de rocha. Da mesma forma, a absorção de $\mathrm{P}$ e $\mathrm{N}$ foram potencializadas com a aplicação conjunta de MA e fosfato de rocha (Tabela 10).

Tabela 10. Rendimento de matéria seca (MS) e quantidades absorvidas de fósforo e nitrogênio de $A$. gayanus cv. Planaltina e $S$. sesban, em função da adubação fosfatada e da inoculação de micorrizas arbusculares.

\begin{tabular}{|c|c|c|c|c|c|c|}
\hline \multirow[b]{2}{*}{ Tratamentos } & \multicolumn{3}{|c|}{ A. gayanus } & \multicolumn{3}{|c|}{ S. sesban } \\
\hline & $\begin{array}{c}\text { MS } \\
\left.\text { (g.vaso-1) }^{-1}\right)\end{array}$ & $\begin{array}{c}\text { Fósforo } \\
\left(\text { mg.vaso-1) }^{-1}\right.\end{array}$ & $\begin{array}{l}\text { Nitrogênio } \\
\left(\text { mg.vaso- }^{-1}\right)\end{array}$ & MS (g.vaso- & $\begin{array}{c}\text { Fósforo } \\
\text { (mg.vaso- } \\
\text { 1) }\end{array}$ & $\begin{array}{l}\text { Nitrogênio } \\
\left(\text { mg.vaso-1) }^{-1}\right.\end{array}$ \\
\hline Testemunha & $3,44 d$ & $1,10 \mathrm{~d}$ & $55,66 \mathrm{~d}$ & $13,51 \mathrm{~d}$ & $1,81 \mathrm{~d}$ & $40,35 d$ \\
\hline Micorriza (M) & $7,12 \mathrm{c}$ & $1,37 \mathrm{c}$ & $98,26 \mathrm{c}$ & $18,42 \mathrm{c}$ & $2,74 \mathrm{c}$ & $59,57 \mathrm{c}$ \\
\hline Fosfato $\left(F_{1}\right)$ & $9,68 b c$ & $1,40 \mathrm{c}$ & $137,45 b$ & $17,88 \mathrm{c}$ & $2,70 \mathrm{c}$ & $60,98 \mathrm{c}$ \\
\hline Fosfato $\left(F_{2}\right)$ & $12,06 \mathrm{~b}$ & $1,48 \mathrm{c}$ & $157,99 \mathrm{~b}$ & $20,11 b c$ & $3,12 b$ & $62,50 \mathrm{c}$ \\
\hline$M+$ Fosfato $\left(F_{1}\right)$ & $15,67 a b$ & $1,62 b$ & $217,81 a$ & $23,40 \mathrm{~b}$ & $4,05 a$ & $78,48 \mathrm{~b}$ \\
\hline$M+$ Fosfato $\left(F_{2}\right)$ & $18,11 \mathrm{a}$ & $1,77 \mathrm{a}$ & $235,43 a$ & $27,06 \mathrm{a}$ & $4,60 \mathrm{a}$ & $82,23 a$ \\
\hline
\end{tabular}

- Médias seguidas de mesma letra, na coluna, não diferem entre si $(P>0,05)$ pelo teste de Tukey.

$-\mathrm{F}_{1}=100 \mathrm{~kg}$ de $\mathrm{P}_{2} \mathrm{O}_{5} \cdot \mathrm{ha}^{-1} ; \mathrm{F}_{1}=200 \mathrm{~kg}$ de $\mathrm{P}_{2} \mathrm{O}_{5} \cdot \mathrm{ha}^{-1}$.

Fonte: Costa \& Paulino (1999c,d; 2001).

\section{Nitrogênio ( $N$ )}

O N é considerado, dentre todos os fatores de produção, como um dos nutrientes mais importantes para a produtividade das gramíneas forrageiras, sendo, depois da água, o principal componenete do protoplama vegetal. Nas plantas, seus teores podem variar de 1 até 3,5\%. Apesar de sua abundância 
na atmosfera sob a forma de $N_{2}$, está presente em pequenas quantidades na maioria dos solos. O N participa ativamente da síntese de compostos orgânicos que formam a estrutura vegetal, tais como aminoaçúcares, aminas, amidas, vitaminas, pigmentos, aminoácidos, proteínas e ácidos nucléicos (Malavolta, 1980; Mengel \& Kirkby, 1982). Atua em diferentes processos metabólicos, fazendo parte da constituição de hormônios e interferindo no processo fotossintético por fazer parte da molécula de clorofila. Ademais, é responsável pelo aparecimento e desenvolvimento dos afilhos, tamanho das folhas e dos colmos, intensidade de florescimento e formação de sementes (Nabinger, 1997). O nitrato $\left(\mathrm{NO}_{3}^{-}\right)$e o amônio $\left(\mathrm{NH}_{4}^{+}\right)$são as formas de $\mathrm{N}$ mais absorvidas pelas raízes e transportadas através do xilema das plantas forrageiras. Parte do amônio é incorporada a compostos orgânicos ainda nas raízes, enquanto que o nitrato é reduzido a amônio para fazer parte dos esqueletos carbônicos da planta. O nitrato é muito móvel na planta e pode ser armazenado nos vacúolos das raízes, colmos e órgãos de reserva (Marschner, 1995).

Com baixa disponibilidade de $\mathrm{N}$ no solo, as plantas manifestarão menor crescimento e, como conseqüência, redução no teor de PB, tornando a forragem deficiente para a adequada nutrição animal. Para pastagens de $P$. guenoarum, Costa \& Saibro (1984) constataram incrementos lineares na produção de MS, nos teores de PB e no número de afilhos/planta com a aplicação de até $400 \mathrm{~kg}$ de N.ha-1. Magalhães et al. (2004), em pastagens de $P$. purpureum cv. Roxo, verificaram que a aplicação de $450 \mathrm{~kg} \cdot \mathrm{ha}^{-1} \cdot \mathrm{ano}^{-1}$ de $\mathrm{N}$ implicou em maior rendimento de MS (7,67 t.ha-1. corte $\left.^{-1}\right)$, que foi significativamente superior à aplicação de $300\left(6,64\right.$ t.ha- ${ }^{-1}$.corte $\left.{ }^{-1}\right)$ ou 150 $\left(5,88\right.$ t.ha ${ }^{-1}$. corte $\left.{ }^{-1}\right)$. O efeito da adubação nitrogenada foi linear, sendo descrito pela equação $Y=4,94+0,005966 X\left(r^{2}=0,99\right)$. A eficiência de produção de MS foi inversamente proporcional às doses aplicadas: 39,$2 ; 22,1$ e $17,0 \mathrm{~kg}$ de $\mathrm{MS} \mathrm{kg}^{-1}$ de $\mathrm{N}$, respectivamente para $150 ; 300$ e $450 \mathrm{~kg}$ de N.ha-

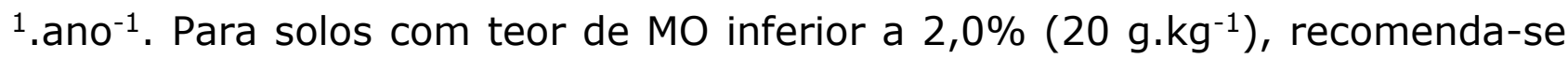
uma aplicação de 40 a $80 \mathrm{~kg}$ de N.ha-1, em cobertura, dois meses após a 
emergência das plantas. Para os sistemas de produção mais intensivos, sugere-se a aplicação de 80 a $120 \mathrm{~kg}$ de N.ha-1, anualmente, parcelada em três a quatro aplicações, durante o período chuvoso, a intervalos de 30 a 45 dias (Costa et al., 2004).

\section{Potássio (K)}

O K tem ação fundamental no metabolismo vegetal, notadamente no processo de fotossíntese, atuando nas reações de transformação da energia luminosa em química, além de participar na síntese de proteínas, na neutralização de ácidos orgânicos e na regulação da pressão osmótica e do pH dentro da planta (Faquin, 1994). Braga \& Yamada (1984) resumem o reflexo direto do $\mathrm{K}$ na fotossíntese: 1 . maior assimilação de $\mathrm{CO}_{2}$, que é o processo primário no qual o carbono inorgânico é transformado em orgânico; 2. maior translocação de carboidratos produzidos nas folhas para os outros órgãos da planta; 3. como decorrência de (1) e (2), maior síntese de sacarose, amido, lipídeos, aminoácidos e proteínas; 4 . uso mais eficiente da água, através do melhor controle na abertura e fechamento dos estômatos; 5. controle dos movimentos foliares (nastias) e, 5. maior eficiência enzimática.

As plantas deficientes em $\mathrm{K}$ apresentam baixas taxas de crescimento, afilhamento reduzido, colmos mais finos, com baixa resistência ao tombamento, alongamento pouco acentuado e a maioria das folhas médias apresentam-se com coloração amarelo-alaranjada e com manchas cloróticas que posteriormente tornam-se necróticas. As plantas bem supridas em $\mathrm{K}$ utilizam a água mais eficientemente, diminuindo a sua demanda para a produção de MS, dentro de certos limites (Malavolta, 1980). Costa \& Paulino (2002) verificaram que a adubação potássica incrementou significativamente os rendimentos de MS e os teores de $\mathrm{N}$ e K da leguminosa arbustiva Cassia rotundifolia, contudo não afetou os teores de Ca e Mg. A DMET foi estimada em $43,8 \mathrm{mg}$ de $\mathrm{K} .\left(\mathrm{dm}^{3}\right)^{-1}$ e o $\mathrm{NCI}$ de $\mathrm{K}$, relacionado com $90 \%$ do rendimento 
máximo de $\mathrm{MS}$, de $16,8 \mathrm{~g}$ de $\mathrm{K} \cdot \mathrm{kg}^{-1}$. A eficiência de utilização de $\mathrm{K}$ foi diretamente proporcional às doses aplicadas. Para Acacia angustissima, a DMET foi estimada em 44,4 mg de K. $\left(\mathrm{dm}^{3}\right)^{-1}$ e o NCI de $17,3 \mathrm{~g}$ de $\mathrm{K} \mathrm{kg}^{-1}$ de solo (Costa et al., 2001) (Tabela 11). Para P. atratum cv. Pojuca, a DMET foi estimada em 52,8 mg de K. $\left(\mathrm{dm}^{3}\right)^{-1}$ e o $\mathrm{NCI}$ de $17,2 \mathrm{~g} \cdot \mathrm{kg}^{-1}$. A eficiência de utilização de $\mathrm{K}$ e os teores de $\mathrm{Ca}$ e $\mathrm{Mg}$ não foram afetados pelos níveis de $\mathrm{K}$ utilizados, enquanto que para $P$. purpureum cv. Cameroon, a DMET foi estimada em $51,7 \mathrm{mg}$ de $\mathrm{K} .\left(\mathrm{dm}^{3}\right)^{-1}$ e o $\mathrm{NCI}$, relacionado com $90 \%$ do rendimento máximo de $M S$, de $19,3 \mathrm{~g} \mathrm{~kg}^{-1}$ (Costa et al., 2004). Para $P$. maximum cv. Centenário, Costa et al. (2004) constataram efeitos significativos da adubação potássica com a aplicação de até $45 \mathrm{mg}$.( $\left.\mathrm{dm}^{3}\right)$. A DMET foi estimada em $51,87 \mathrm{mg}$ de $\mathrm{K} .\left(\mathrm{dm}^{3}\right)^{-1}$ e o NCI de $\mathrm{K}$ de $18,8 \mathrm{~g}^{\mathrm{kg}} \mathrm{kg}^{-1}$ (Tabela 12).

Tabela 11. Rendimento de matéria seca (MS), eficiência de utilização do potássio (EUK), teores de nitrogênio, fósforo, cálcio, magnésio e potássio de $A$. angustissima, em função da fertilização potássica.

\begin{tabular}{|c|c|c|c|c|c|c|c|}
\hline \multirow{2}{*}{$\begin{array}{c}\text { Doses de K } \\
\text { mg. }\left(\mathrm{dm}^{3}\right)\end{array}$} & \multirow{2}{*}{$\begin{array}{c}\text { MS } \\
\text { (g.vaso-1) }^{-1}\end{array}$} & \multirow{2}{*}{$\begin{array}{c}\text { EUK } \\
\text { g MS.mg-1 } \\
\mathrm{K}\end{array}$} & Nitrogênio & Fósforo & Cálcio & Magnésio & Potássio \\
\hline & & & \multicolumn{5}{|c|}{- g.kg-1 } \\
\hline 0 & $5,33 d$ & $3,64 \mathrm{c}$ & $27,3 \mathrm{~b}$ & $1,91 \mathrm{ab}$ & $7,34 \mathrm{a}$ & $3,22 \mathrm{a}$ & $14,64 \mathrm{c}$ \\
\hline 15 & $9,29 \mathrm{c}$ & $5,26 \mathrm{~b}$ & $29,5 a b$ & $1,97 \mathrm{a}$ & $7,07 \mathrm{a}$ & $3,65 \mathrm{a}$ & $17,67 \mathrm{~b}$ \\
\hline 30 & $11,85 \mathrm{~b}$ & $6,17 \mathrm{a}$ & $31,6 \mathrm{a}$ & $1,84 a b$ & $6,95 \mathrm{a}$ & $3,17 \mathrm{a}$ & $19,20 \mathrm{ab}$ \\
\hline 45 & $12,88 a b$ & $6,24 \mathrm{a}$ & $28,9 a b$ & $1,80 \mathrm{~b}$ & $7,66 \mathrm{a}$ & $2,97 \mathrm{a}$ & $20,64 \mathrm{a}$ \\
\hline 60 & $13,29 a$ & $6,38 a$ & $29,5 \mathrm{a}$ & $1,77 \mathrm{~b}$ & $6,73 a$ & $3,74 \mathrm{a}$ & $20,82 \mathrm{a}$ \\
\hline
\end{tabular}

Tabela 12. Rendimento de matéria seca (MS), eficiência de utilização do potássio (EUK), teores de proteína bruta (PB), fósforo e potássio de Panicum maximum cv. Centenário, em função da fertilização potássica.

\begin{tabular}{|c|c|c|c|c|c|}
\hline \multirow{2}{*}{$\begin{array}{r}\text { Níveis de K } \\
\mathrm{mg} .\left(\mathrm{dm}^{3}\right) \\
\end{array}$} & \multirow{2}{*}{$\begin{array}{c}\text { MS } \\
\left.\text { (g.vaso }^{-1}\right) \\
\end{array}$} & \multirow{2}{*}{$\begin{array}{c}\text { EUK } \\
\text { g MS. } \text { m }^{-1} \mathrm{~K} \\
\end{array}$} & PB & Fósforo & Potássio \\
\hline & & & \multicolumn{3}{|c|}{ - } \\
\hline 0 & $2,35 d$ & $1,65 \mathrm{c}$ & $12,45 \mathrm{a}$ & $0,156 \mathrm{c}$ & $1,42 \mathrm{c}$ \\
\hline 15 & $3,98 \mathrm{c}$ & $2,27 \mathrm{~b}$ & $11,02 \mathrm{~b}$ & $0,169 \mathrm{a}$ & $1,75 b$ \\
\hline 30 & $5,87 \mathrm{~b}$ & $3,14 \mathrm{a}$ & $10,33 b$ & $0,170 \mathrm{a}$ & $1,87 \mathrm{a}$ \\
\hline 45 & $6,11 \mathrm{ab}$ & $3,20 \mathrm{a}$ & $12,56 \mathrm{a}$ & $0,162 b$ & $1,91 \mathrm{a}$ \\
\hline 60 & $6,55 a$ & $3,40 a$ & $11,95 \mathrm{a}$ & $0,173 \mathrm{a}$ & $1,93 a$ \\
\hline
\end{tabular}

- Médias seguidas de mesma letra, na coluna, não diferem entre si $(P>0,05)$ pelo teste de Tukey. 
Fonte: Costa et al. (2004).

\section{Recomendações para a Adubação de Pastagens}

As recomendações devem ser formuladas a partir da interpretação dos resultados da análise química do solo, considerando-se os requerimentos nutricionais específicos para as plantas forrageiras, as quais podem ser classificadas em três grupos: Grupo I (alta exigência); Grupo II (média exigência) e Grupo III (baixa exigência).

Nas Tabelas 13, 14 e 15 são apresentadas as recomendações para a calagem e adubações fosfatada e potássica das gramíneas e leguminosas forrageiras selecionadas como promissoras para a formação de pastagens na Amazônia. No entanto, a adoção de práticas adequadas de manejo, que envolva a utilização de germoplasma forrageiro responsivo à aplicação de nutrientes e com alta capacidade de competição com as plantas invasoras; sistemas e pressões de pastejo compatíveis com a manutenção do equilíbrio do ecossistema e que possibilitem uma eficiente reciclagem de nutrientes, são fatores determinantes para maximizar os efeitos da calagem e adubação.

Tabela 13. Clasificação das gramíneas e leguminosas forrageiras, em função de suas exigências em fertilidade do solo.

\begin{tabular}{|c|c||}
\hline Grupos & Espécies \\
\hline \hline Gramíneas Grupo I & $\begin{array}{r}\text { Panicum maximum cvs. Centenário, Massai, Mombaça, Vencedor, } \\
\text { Tanzânia-1, Tobiatã; Pennisetum purpureum }\end{array}$ \\
\hline Gramíneas Grupo II & $\begin{array}{c}\text { Andropogon gayanus cv. Planaltina, Brachiaria brizantha. cvs. Marandu, } \\
\text { Xaraés }\end{array}$ \\
\hline Gramíneas Grupo III & $\begin{array}{c}\text { Brachiaria dictyoneura, B. humidicola, Paspalum atratum cv. Pojuca, } \\
\text { Setaria sphacelata }\end{array}$ \\
\hline \hline Leguminosas Grupo I & Arachis pintoi, Cajanus cajan, Leucaena leucocephala \\
\hline Leguminosas Grupo II & $\begin{array}{c}\text { Centrosema acutifolium, C. brasilianum, } \\
\text { C. macrocarpum, Pueraria phaseoloides }\end{array}$ \\
\hline Leguminosas Grupo III & $\begin{array}{r}\text { Calopogonium mucunoides, Desmodium ovalifolium, Stylosanthes } \\
\text { capitata, S. guianensis, S. macrocephala }\end{array}$ \\
\hline
\end{tabular}


Costa, N.L., Paulino, V.T., Townsend, C.R. et a. Calagem e adubação de pastagens na Amazônia. PUBVET, Londrina, V. 2, N. 43, Art\#413, Out5, 2008.

Tabela 14. Sugestões para a adubação fosfatada de gramíneas e leguminosas forrageiras, em função de seus requerimentos nutricionais e da disponibilidade de $\mathrm{P}$ no solo.

\begin{tabular}{|c|c|c|c|}
\hline \multirow{2}{*}{ Forrageiras } & \multirow{2}{*}{$\begin{array}{l}\text { Teores de P no solo } \\
\left(\mathrm{mg} .\left(\mathrm{dm}^{3}\right)^{-1}\right)\end{array}$} & \multicolumn{2}{|c|}{ Doses de fósforo $\left(\mathrm{kg} \mathrm{de} \mathrm{P}_{2} \mathrm{O}_{5} \cdot \mathrm{ha}^{-1}\right)$} \\
\hline & & Estabelecimento & Manutenção Anual \\
\hline \multirow[t]{4}{*}{ Gramíneas Grupo I } & $<3,0$ & 120 & 80 \\
\hline & $3,1-6,0$ & 80 & 60 \\
\hline & $6,1-9,0$ & 60 & 40 \\
\hline & $>9,1$ & 40 & 30 \\
\hline \multirow[t]{4}{*}{ Gramíneas Grupo II } & $<3,0$ & 80 & 60 \\
\hline & $3,1-6,0$ & 60 & 40 \\
\hline & $6,1-9,0$ & 40 & 30 \\
\hline & $>9,1$ & 20 & 20 \\
\hline \multirow[t]{4}{*}{ Gramíneas Grupo III } & $<3,0$ & 60 & 40 \\
\hline & $3,1-6,0$ & 40 & 20 \\
\hline & $6,1-9,0$ & 20 & 20 \\
\hline & $>9,1$ & -- & 20 \\
\hline \multirow[t]{4}{*}{ Leguminosas Grupo I } & $<3,0$ & 120 & 80 \\
\hline & $3,1-6,0$ & 80 & 60 \\
\hline & $6,1-9,0$ & 60 & 40 \\
\hline & $>9,1$ & 40 & 30 \\
\hline \multirow[t]{4}{*}{ Leguminosas Grupo II } & $<3,0$ & 80 & 40 \\
\hline & $3,1-6,0$ & 60 & 30 \\
\hline & $6,1-9,0$ & 40 & 20 \\
\hline & $>9,1$ & 20 & -- \\
\hline \multirow[t]{4}{*}{ Leguminosas Grupo III } & $<3,0$ & 40 & 20 \\
\hline & $3,1-6,0$ & 30 & 20 \\
\hline & $6,1-9,0$ & 20 & 20 \\
\hline & $>9,1$ & -- & -- \\
\hline
\end{tabular}


Costa, N.L., Paulino, V.T., Townsend, C.R. et a. Calagem e adubação de pastagens na Amazônia. PUBVET, Londrina, V. 2, N. 43, Art\#413, Out5, 2008.

Tabela 15. Recomendações para a adubação potássica de gramíneas e leguminosas forrageiras, em função de seus requerimentos nutricionais e da disponibilidade de $\mathrm{K}$ no solo.

\begin{tabular}{|c|c|c|c|}
\hline \multirow{2}{*}{ Forrageiras } & \multirow{2}{*}{$\begin{array}{l}\text { Teores de K no solo } \\
\left(\mathrm{cmol}_{\mathrm{c}} \cdot\left(\mathrm{dm}^{3}\right)^{-1}\right)\end{array}$} & \multicolumn{2}{|c|}{ Doses de potássio $\left(\mathrm{kg}\right.$ de $\left.\mathrm{K}_{2} \mathrm{O} \cdot \mathrm{ha}^{-1}\right)$} \\
\hline & & Estabelecimento & Manutenção Anual \\
\hline \multirow{4}{*}{$\begin{array}{l}\text { Gramíneas } \\
\text { Grupo I }\end{array}$} & $<0,05$ & 120 & 60 \\
\hline & $0,06-0,10$ & 80 & 40 \\
\hline & $0,11-0,20$ & 60 & 30 \\
\hline & $>0,21$ & 40 & 20 \\
\hline \multirow{4}{*}{$\begin{array}{l}\text { Gramíneas } \\
\text { Grupo II }\end{array}$} & $<0,05$ & 80 & 40 \\
\hline & $0,06-0,10$ & 60 & 30 \\
\hline & $0,11-0,20$ & 40 & 20 \\
\hline & $>0,21$ & 20 & 20 \\
\hline \multirow{4}{*}{$\begin{array}{l}\text { Gramíneas } \\
\text { Grupo III }\end{array}$} & $<0,05$ & 60 & 40 \\
\hline & $0,06-0,10$ & 40 & 20 \\
\hline & $0,11-0,20$ & 20 & 20 \\
\hline & $>0,21$ & -- & 20 \\
\hline \multirow{4}{*}{$\begin{array}{c}\text { Leguminosas } \\
\text { Grupo I }\end{array}$} & $<0,05$ & 90 & 60 \\
\hline & $0,06-0,10$ & 60 & 40 \\
\hline & $0,11-0,20$ & 40 & 30 \\
\hline & $>0,21$ & 20 & 20 \\
\hline \multirow{4}{*}{$\begin{array}{c}\text { Leguminosas } \\
\text { Grupo II }\end{array}$} & $<0,05$ & 80 & 40 \\
\hline & $0,06-0,10$ & 60 & 30 \\
\hline & $0,11-0,20$ & 40 & 20 \\
\hline & $>0,21$ & 20 & -- \\
\hline \multirow{4}{*}{$\begin{array}{l}\text { Leguminosas } \\
\text { Grupo III }\end{array}$} & $<0,05$ & 40 & 30 \\
\hline & $0,06-0,10$ & 30 & 20 \\
\hline & $0,11-0,20$ & 20 & 10 \\
\hline & $>0,21$ & -- & -- \\
\hline
\end{tabular}

\section{Referências Bibliográficas}

AZEVEDO, P.G.C. de.; SOUZA, F.R.S. de. Fertilizantes para adubação de pastagens de capimcolonião (Panicum maximum) em Altamira-Pará. In: REUNIÃO ANUAL DA SOCIEDADE BRASILEIRA DE ZOOTECNIA, 19., 1982, Piracicaba. Anais... Piracicaba: SBZ, 1982. p.350.

BAREA, J.M.; ÁZCON-AGUILAR, G. Mycorrhizas and their significance in nodulating nitrogenfixing plants. Advances in Agronomy, New York, v.36, p.1-54, 1983.

BAREA, J.M.; ÁZCON, R.; HAYMAN, D.S. Possible synergistic interactions between Endogone and phosphate-solubilizing bacteria in low phosphate soils. In: SANDERS, F.E.; MOSSE, B.; TINKER, P.B. (Eds.). Endomycorrhizas. London, Academic Press, 1975. p.373-389.

BRAGA, J.M.; YAMADA, T. Uso eficiente de fertilizantes potássicos. In; SIMPÓSIO SOBRE FERTILIZANTES NA AGRICULTURA BRASILEIRA, 1., 1984, Brasília. Anais... Brasília: POTAFOS, 1984. p.291-321. 
Costa, N.L., Paulino, V.T., Townsend, C.R. et a. Calagem e adubação de pastagens na Amazônia. PUBVET, Londrina, V. 2, N. 43, Art\#413, Out5, 2008.

COSTA, N. de L. Adubação nitrogenada e consorciação de capim-elefante (Pennisetum purpureum cv. Cameroon) com leguminosas forrageiras tropicais. Pesquisa Agropecuária Brasileira, Brasília, v.30, n.3, p.401-408, 1995.

COSTA, N. de L. Avaliação agronômica de gramíneas forrageiras sob três níveis de adubação fosfatada. Porto Velho: Embrapa-UEPAE Porto Velho. 1989. 4p. (Embrapa-UEPAE Porto Velho. Comunicado Técnico, 80).

COSTA, N. de L. Efeito de micorrizas vesículo-arbusculares sobre o crescimento e nutrição mineral do sorgo forrageiro. Boletim do Museu Paraense Emílio Goeldi, Série Botânica, Belém, v.12, n.1, p.7-13, 1996b.

COSTA, N. de L. Efeito do nitrogênio mineral e leguminosas sobre a produção de forragem e composição química de capim-elefante cv. Cameroon. Porto Velho: Embrapa Rondônia, 1996c. 16p. (Embrapa Rondônia. Boletim de Pesquisa, 13).

COSTA, N. de L. Programa de pesquisa com pastagens em Rondônia - 1975/1995. Porto Velho: Embrapa Rondônia, 1996a. 46p. (Embrapa Rondônia. Documentos, 32).

COSTA, N. de L. Utilização de fosfatos naturais em pastagens tropicais. Disponível em <http.www. agronet.com.br/cgi-bin/agronews.pl.id=7243> Acesso em 12.08.1999.

COSTA, N. de L.; ALVES, P.M.P.; OLIVEIRA, J.R. da C. Avaliação de cultivares de guandu (Cajanus cajan (L.)Millsp.) sob dois níveis de fertilização fosfatada em Porto Velho, Rondônia, Brasil. In: REUNIÓN DE LA RED INTERNACIONAL DE EVALUACIÓN DE PASTOS TROPICALES AMAZÔNIA, 1., 1990. Lima, Peru. Memórias... Cali, Colômbia: CIAT, 1990a. v.2, p.725-729.

COSTA, N. de L.; DIONÍSIO, J.A.; ANGHINONI, I. Influência de fungos micorrízicos vesículoarbusculares, fontes e doses de fósforo sobre o crescimento da aveia forrageira. Pesquisa Agropecuária Brasileira, Brasília, v.24, n.8, p.979-986, 1989b.

COSTA, N. de L.; GONÇALVES, C.A.; BOTELHO, S.M.; OLIVEIRA, J.R. da C. Efeito da calagem e adubação fosfatada na produção de forragem de Andropogon gayanus cv. Planaltina. Porto Velho: Embrapa-UEPAE Porto Velho, 1990b. 5p. (Embrapa-UEPAE Porto Velho. Comunicado Técnico, 85).

COSTA, N. de L.; GONÇALVES, C.A.; BOtELHO, S.M.; OLIVEIRA, J.R. da C. Níveis de calagem e fósforo na formação de pastagens de Brachiaria humidicola em Rondônia. Porto Velho: Embrapa-UEPAE Porto Velho, 1989a. 5p. (Embrapa-UEPAE Porto Velho. Comunicado Técnico, 82).

COSTA, N. de L.; GONÇALVES, C.A.; OLIVEIRA, J.R. da C. Efeito de níveis de fósforo, enxofre e micronutrientes sobre o crescimento de Brachiaria humidicola consorciada com leguminosas em Porto Velho-RO. Porto Velho: Embrapa-UEPAE Porto Velho, $1989 \mathrm{f}$. 5p. (Embrapa-UEPAE Porto Velho. Comunicado Técnico, 78).

COSTA, N. de L.; GONÇALVES, C.A.; OliVEIRA, J.R. da C. Nutrientes limitantes ao crescimento de Brachiaria humidicola consorciada com leguminosas em Porto VelhoRO. Porto Velho: Embrapa-UEPAE Porto Velho, 1989c. 4p. (Embrapa-UEPAE Porto Velho. Comunicado Técnico, 70).

COSTA, N. de L.; GONÇALVES, C.A.; RODRIGUES, A.N.A. Nutrientes limitantes ao crescimento de Brachiaria decumbens em Rondônia. In: CONGRESSO BRASILEIRO DE CIÊNCIA DO SOLO, 27., Rio de Janeiro, 1997. Anais... Rio de janeiro, SBCS, 1997a. $3 p$. (CD-ROM)

COSTA, N. de L.; GONÇALVES, C.A.; TOWNSEND, C.R. Avaliação agronômica de Panicum maximum cv. Tobiatã em consorciação com leguminosas forrageiras tropicais. Pesquisa Agropecuária Brasileira, Brasília, v.33, n.3, p.363-367, 1998b. 
Costa, N.L., Paulino, V.T., Townsend, C.R. et a. Calagem e adubação de pastagens na Amazônia. PUBVET, Londrina, V. 2, N. 43, Art\#413, Out5, 2008.

COSTA, N. de L.; MAGALHÃES, J.A.; TOWNSEND, C.R.; PEREIRA, R.G. de A. Reciclagem de nutrientes em pastagens. I. Nitrogênio. Disponível em <http.www.agronet.com.br/cgibin/agronews.pl.id=7583> Acesso em 22.08.2000b.

COSTA, N. de L.; MAGALHÃES, J.A.; TOWNSEND, C.R.; PEREIRA, R.G. de A. Reciclagem de nutrientes em pastagens. II. Fósforo. Disponível em <http.www.agronet.com.br/cgibin/agronews.pl.id=7679> Acesso em 22.08.2000c.

COSTA, N. de L.; MAGALHÃES, J.A.; TOWNSEND, C.R.; PEREIRA, R.G. de A. Reciclagem de nutrientes em pastagens. III. Potássio. Disponível em <http.www.agronet.com.br/cgibin/agronews.pl.id=7703> Acesso em 22.08.2000d.

COSTA, N. de L.; MAGALHÃES, J.A.; TOWNSEND, C.R.; PEREIRA, R.G. de A. Reciclagem de nutrientes em pastagens. IV. Enxofre. Disponível em <http.www.agronet.com.br/cgibin/agronews.pl.id=7660> Acesso em 22.08.2000e.

COSTA, N de L.; PAULINO, V.T. Adubação potássica em Cassia rotundifolia. Porto Velho: Embrapa Rondônia, 2002. 4p. (Embrapa Rondônia. Comunicado Técnico, 215).

COSTA, N. de L.; PAULINO, V.T. Efeito de fungos endomicorrízicos e doses de fósforo sobre o crescimento e nutrição mineral de Stylosanthes capitata CIAT-10280 e Zornia glabra CIAT-7847. Agronomia Sulriograndense, Porto Alegre, v.25, n.1, p.83-92, 1989.

COSTA, N. de L.; PAULINO, V.T. Efeito de micorrizas arbusculares sobre o crescimento e composição química de Brachiaria humidicola. Macapá: Embrapa Amapá, 1999b. 14p. (Embrapa Amapá. Boletim de Pesquisa, 30).

COSTA, N. de L.; PAULINO, V.T. Efeito de micorrizas vesículo-arbusculares sobre o crescimento e absorção de fósforo de Andropogon gayanus cv. Planaltina. Revista de Agricultura, Piracicaba, v.66, n.2, p.157-166, 1991.

COSTA, N. de L.; PAULINO, V.T. Efeito de micorrizas vesículo-arbusculares sobre o crescimento e absorção de fósforo de gramíneas e leguminosas forrageiras tropicais. In: REUNIÓN DE LA RED INTERNACIONAL DE EVALUACIÓN DE PASTOS TROPICALES - AMAZÔNIA, 1., 1990, Lima. Memórias... Cali, Colômbia: CIAT, 1990. v.2. p.773-735.

COSTA, N. de L.; PAULINO, V.T. Efeito de micorrizas vesículo-arbusculares sobre o crescimento e composição química de Pueraria phaseoloides. In: SEMINÁRIO DE PESQUISA AGROPECUÁRIA DO PIAUÍ, 8., Teresina, 1997. Anais... Teresina: Embrapa Meio Norte, 1997. p.183-187.

COSTA, N. de L.; PAULINO, V.T. Eficiência de micorrizas arbusculares e da adubação fosfatada em Andropogon gayanus cv. Planaltina. Macapá: Embrapa Amapá, 1999c. 13p. (Embrapa Amapá. Boletim de Pesquisa, 31).

COSTA, N. de L.; PAULINO, V.T. Growth response of Acacia angustissima to vesiculararbuscular mycorrhizal inoculation. Forest, Farm, and Community Tree Research Reports, Morrilton, v.4, p.51-53, 1999e.

COSTA, N. de L.; PAULINO, V.T. Phosphorus levels and sources affect growth, nodulation, and chemical composition of pigeonpea. Nitrogen Fixing Tree Research Reports, Bangkok, v.11, p.68-70. 1993.

COSTA, N. de L.; PAULINO, V.T. Nutrientes limitantes ao crescimento de Panicum maximum cv. Centenário. Porto Velho: Embrapa Rondônia, 2001. 4p. (Comunicado Técnico, 196).

COSTA, N. de L.; PAULINO, V.T. Response of Acacia angustissima to levels and sources of phosphate fertilization. Forest, Farm, and Community Tree Research Reports, Morrilton, v.4, p.54-56, 1999a. 
Costa, N.L., Paulino, V.T., Townsend, C.R. et a. Calagem e adubação de pastagens na Amazônia. PUBVET, Londrina, V. 2, N. 43, Art\#413, Out5, 2008.

COSTA, N. de L.; PAULINO, V.T. Resposta de Andropogon gayanus cv. Planaltina à inoculação de micorrizas arbusculares e à fertilização com fosfato de rocha. Macapá: Embrapa Amapá, 1999d. 12p. (Embrapa Amapá. Boletim de Pesquisa, 32).

COSTA, N. de L.; LEÔNIDAS, F.C.; PAULINO, V.T. Efeito de níveis de fosfogesso sobre a produção de forragem e composição química de Brachiaria brizantha cv. Marandu. In: SIMPÓSIO AGROPEUÁRIO E FLORESTAL DO MEIO-NORTE, 1., 1994, Teresina. Anais... Teresina: Embrapa Meio-Norte, 1997c. p.60-64.

COSTA, N. de L.; PAULINO, V.T.; CARDELLI, M.A.; RODRIGUES, A.N.A.; OLIVEIRA, J.R. da C. Efeito de fontes e doses de fósforo sobre a produção de forragem de Andropogon gayanus cv. Planaltina. Revista de Agricultura, Piracicaba, v.68, n.3, p.287-294, 1993.

COSTA, N. de L.; PAULINO, V.T.; COSTA, R.S. C. da. Efeito de micorrizas arbusculares sobre o crescimento e nutrição mineral de Brachiaria brizantha cv. Marandu. Porto Velho, Embrapa-CPAF Rondônia, 1997b. 14p. (Embrapa-CPAF Rondônia. Boletim de Pesquisa, 15).

COSTA, N. de L.; PAULINO, V.T.; OLIVEIRA, J.R. da C.; RODRIGUES, A.N.A.; LEÔNIDAS, F. das $C$. Efeito de calagem e fertilização fosfatada sobre o rendimento de forragem e composição química da leucaena (Leucaena leucocephala cv. Cunninghan) nos cerrados de Rondônia, Brasil. In: REUNIÓN DE LA RED INTERNACIONAL DE EVALUACIÓN EN PASTOS TROPICALES SABANAS, 1., 1992, Brasília. Memórias... Cali, Colômbia: CIAT, 1992. p.415-419.

COSTA, N. de L.; PAULINO, V.T.; RODRIGUES, A.N.A. Effect of vesicular-arbuscular mycorrhiza and phosphate fertilization on growth, nodulation, and nitrogen and phosphorus uptake of pigeon pea. Nitrogen Fixing Tree Research Reports, Bangkok, v.8, p.123-125, 1990c.

COSTA, N. de L.; PAULINO, V.T.; RODRIGUES, A.N.A.; TOWNSEND, C.R. Nutrientes limitantes ao crescimento de Paspalum atratum. Pasturas Tropicales, Cali, v.20, n.2, p.46-48, 1998a.

COSTA, N. de L.; PAULINO, V.T.; RODRIGUES, A.N.A.; TOWNSEND, C.R.; MAGALHÃES, J.A. Calagem e adubação de pastagens. In: COSTA, N de L. (Ed.) Formação, manejo e recuperação de pastagens em Rondônia. Porto Velho: Embrapa Rondônia, 2004. p.81-115.

COSTA, N. de L.; PAULINO, V.T.; SCHAMMAS, E.A. Efeito de micorrizas vesículo-arbusculares e doses de fósforo sobre o crescimento e absorção de fósforo e nitrogênio de Desmodium ovalifolium CIAT-350. Pasturas Tropicales, Cali, v.11, n.3, p.16-20, 1989d.

COSTA, N. de L.; PAULINO, V.T.; SCHAMMAS, E.A. Produção de forragem, composição mineral e nodulação do guandu afetadas pela calagem e adubação fosfatada. Revista Brasileira de Ciência do Solo, Piracicaba, v.13, n.1, p.51-58, 1989e.

COSTA, N. de L.; RODRIGUES, A.N.A.; PAULINO, V.T. Resposta de Acacia angustissima à fertilização potássica. Porto Velho: Embrapa Rondônia, 2001. 4p. (Embrapa Rondônia. Comunicado Técnico, 198).

COSTA, N. de L.; SAIBRO, J.C. de. Adubação nitrogenada, épocas e alturas de corte em Paspalum guenoarum Arech. Agronomia Sulriograndense, Porto Alegre, v.20, n.1, p.33-49, 1984.

COSTA, N. de L.; TOWNSEND, C.R. Resposta de ecótipos de Andropogon gayanus à fertilização fosfatada. Porto Velho, EMBRAPA-CPAF Rondônia, 1996. 4p. (Embrapa Rondônia. Comunicado Técnico, 111).

COSTA, N de L.; TOWNSEND, C.R.; MAGALHÃES, J.A.; OLIVEIRA, J.R. da C. Limitações de fertilidade do solo para o crescimento de Brachiaria brizantha cv. Xaraés. Porto Velho: Embrapa Rondônia, 2004b. 3p. (Embrapa Rondônia. Comunicado Técnico, 280).

COSTA, N. de L.; TOWNSEND, C. R.; PEREIRA, R. G. de A.; MAGALHÃES, J. A.; SILVA NETTO, F. G. da.; TAVARES, A. C. Tecnologias para a produção animal em Rondônia - 1975/2001. Porto Velho: Embrapa Rondônia, 2003. 26 p. (Documentos, 70). 
Costa, N.L., Paulino, V.T., Townsend, C.R. et a. Calagem e adubação de pastagens na Amazônia. PUBVET, Londrina, V. 2, N. 43, Art\#413, Out5, 2008.

CRESS, W.A.; THRONEBERRY, G.O.; LINDSY, D.L. Kinetics of phosphorus absorption by mycorrhizal and non-mycorrhizal tomato roots. Plant Physiology, Lancaster, v.64, p.484487, 1979.

FAQUIN, V. Nutrição mineral de plantas. Lavras: FAEPE, 1994. 227p.

FENSTER, W.E.; LEÓN, L.A. Considerações sobre a fertilização fosfatada no estabelecimento e persistência de pastagens em solos ácidos e de baixa fertilidade na América latina Tropical. In: TERGAS, L.E.; SANCHEZ, P.; SERRÃO, E.A.S. (Eds.). Produção de pastagens em solos ácidos dos trópicos. São Paulo: Editerra, 1978. p.127-140.

GONÇALVES, C.A.; LEÔNIDAS, F. das C.; SALGADO, L.T.; COSTA, N. de L. Efeito da calagem no estabelecimento de Brachiaria humidicola em Rondônia. In: REUNIÃO ANUAL DA SOCIEDADE BRASILEIRA DE ZOOTECNIA, 23., 1986, Campo Grande. Anais... Campo Grande: SBZ, 1986, p.202.

GONÇALVES, C.A.; COSTA, N. de L.; OLIVEIRA, J.R. da C. Nutrientes limitantes ao crescimento de duas gramíneas forrageiras tropicais em Porto Velho, Rondônia, Brasil. In: REUNIÓN DE LA RED INTERNACIONAL DE EVALUACIÓN DE PASTOS TROPICALES AMAZONIA, 1., 1990, Lima, Peru. Memórias... Cali, Colombia: CIAT, 1990a. v.2, p.721723.

GONÇALVES, C.A.; COSTA, N. de L.; OLIVEIRA, J.R. da. Efeito de níveis de fósforo, enxofre e micronutrientes em duas gramíneas forrageiras tropicais. In: REUNIÓN DE LA RED INTERNACIONAL DE EVALUACIÓN DE PASTOS TROPICALES - AMAZÔNIA, 1, 1990, Lima, Peru. Memórias... Cali, Colômbia: CIAT, 1990b. v.2. p.717-719.

HOWELER, R.H.; CADAVID, L.F.; BURCKHARDT, E. Response of cassava to VA mycorrhzal inoculation and phosphorus apllication in greenhouse and field experiments. Plant and Soil, The Hague, v.69, p.327-339, 1982.

ITALIANO, E.C.; MORAES, E. de; CANTO, A. do C. Fertilização de pastagem de capimcolonião em degradação. Manaus: Embrapa-UEPAE Manaus, 1982. 3p. (Embrapa-UEPAE Manaus. Comunicado Técnico, 31).

LOPES, E.S.; SIQUEIRA, J.O.; ZAMBOLIM, L. Caracterização das micorrizas vesiculararbuscular (MVA) e seus efeitos no crescimento das plantas. Revista Brasileira de Ciência do Solo, Piracicaba, v.7, n.1, p.1-19, 1983

MAGALHÃES, J.A.; LOPES, E.A.; RODRIGUES, B.H.N.; COSTA, N. de L.; BARROS, N.N.; MATTEI, D.A. Efeito e nitrogênio e da idade de corte na produção de matéria seca do capimelefante cv. Cameroon Roxo. In: CONGRESSO INTERNACIONAL DE ZOOTECNIA, 6., 2004, Brasília. Anais... Brasília: ABZ, 2004. 4p. (CD-ROM).

MALAVOLTA, E. Elementos de nutrição mineral de plantas. São Paulo: Agronômica Ceres, 1980. 251p.

MARSCHNER, H. Mineral nutrition in higher plants. Berlin: Academic Press, 1995. 674p.

MCCORMICK, L.H.; BORDEN, F.Y. Phosphate fixation by aluminum in plants roots. Soil Science of America Proceedings, Madison, v.36, p.799-802, 1972.

MENGEL, K.; KIRKBY, E.A. Principles of plant nutrition. Bern: International Potash Institute, 1982. 655p.

NABINGER, C. Eficiência do uso de pastagens: disponibilidade e perdas de forragem. In: SIMPÓSIO SOBRE MANEJO DA PASTAGEM, 14., 1997, Piracicaba. Anais... Piracicaba: FEALQ, 1997. p.213-251.

PAULINO, V.T.; COSTA, N. de L.; LUCENA, M.A.C. de.; SCHAMMAS, E.A.; FERRARI JÚNIOR, E. Resposta de Brachiaria brizantha cv. Marandu à calagem e à fertilização fosfatada em um solo ácido. Pasturas Tropicales, Cali, v.16, n.2, p.34-41, 1994. 
Costa, N.L., Paulino, V.T., Townsend, C.R. et a. Calagem e adubação de pastagens na Amazônia. PUBVET, Londrina, V. 2, N. 43, Art\#413, Out5, 2008.

PAULINO, V.T.; PAULINO, T.S.; COSTA, N de L.; LUCENA, M.A.C. Calagem, cobalto e molibdênio no desenvolvimento de Galactia striata. In: REUNIÃO ANUAL DA SOCIEDADE BRASILEIRA DE ZOOTECNIA, 40., 2003, Santa Maria. Anais... Santa Maria: SBZ, 2003. 5p. (CD-ROM).

RHODES, L.H.; GERDEMANN, J.W. Phosphate uptake zones of mycorrhizal and non-mycorrhizal onions. New Phytologist, London, v.75, p.755-761, 1975.

SALINAS, J.G. Fertilización de pastos en suelos ácidos de los trópicos. Cali: CIAT, 1987. $215 p$.

SANZONOWICZ, C.; GOEDERT, W.J. Uso de fosfatos naturais em pstagens. In: SIMPÓSIO SOBRE MANEJO DA PASTAGEM, 7., 1985, Piracicaba. Anais... Piracicaba: ESALQ, 1985, p.235267.

SERRÃO, E.A.S.; FALESI, I.C.; VEIGA, J.B da; TEIXEIRA NETO, J.F. Productivity of cultivated pastures on low fertility soil in the Amazon of Brazil. In: SANCHEZ, P.A.; TERGAS, L.E. (Eds.). Pasture production in acid soils. Cali, Colombia: CIAT, 1979. p.257-280.

TOWNSEND, C. R.; COSTA, N. de L.; MENDES, A. M.; PEREIRA, R. G. de A.; MAGALhÃES, J. A. Limitações nutricionais do solo sob pastagem degradada de Brachiaria brizantha cv. Marandu em Porto Velho, Rondônia. Porto Velho: Embrapa Rondônia, 2003. 4p. (Embrapa Rondônia. Comunicado Técnico, 255).

ZAMBOLIM, L.; SIQUEIRA, J.O. Importância e potencial das associações micorrízicas para a agricultura. Belo Horizonte: Epamig, 1985, 36p. (Epamig. Documentos, 26). 